\title{
Idiopathic thrombocytopenic purpura: predictors of chronic disease
}

\author{
L G Robb, K Tiedeman
}

\begin{abstract}
We studied the extent to which patient characteristics influenced outcome in childhood idiopathic thrombocytopenic purpura in a historical cohort of 289 children over a 20 year period (1968-87). Outcome was classified as acute or chronic depending on whether the platelet count had returned to normal $\left(150 \times 10^{9} / 1\right)$ by six months after diagnosis. Fifty three cases $(18 \%)$ had chronic idiopathic
\end{abstract} thrombocytopenic purpura.

The likelihood of chronic disease was determined by logistic regression analysis of five patient variables: age, sex, season of onset of symptoms, history of recent viral illness, and duration of symptoms at presentation. A history of symptoms of $>14$ days at presentation, adjusted for the other variables, was strongly predictive of chronic idiopathic thrombocytopenic purpura; the other variables did not significantly affect outcome.

At 28 days after diagnosis $138(47 \%)$ of the study cohort had normal platelet counts. Children whose platelet counts were $<150 \times 10^{9} / 1$ had a threefold risk of progressing to chronic idiopathic thrombocytopenic purpura, which increased to fivefold if counts were $<50 \times 10^{9} / 1$. Two thirds of patients in the chronic group, irrespective of treatment, remained thrombocytopenic two years after diagnosis.

We conclude that a history of symptoms for greater than two weeks at presentation is strongly predictive of chronic idiopathic thrombocytopenic purpura. If platelet counts are subnormal 28 days after diagnosis the risk of chronic idiopathic thrombocytopenic purpura is increased with prolonged thrombocytopenia being very likely if platelet counts remain low three months after diagnosis.

Royal Children's Hospital, Melbourne, Australia, Department of Laboratory Haematology L G Robb

Department of Haematology and Oncology

$\mathrm{K}$ Tiedeman

Correspondence to: Dr L G Robb, Department of

Diagnostic Haematology,

The Royal Melbourne

Hospital,

Victoria 3050

Australia.

Accepted 29 January 1990 cal activities. A range of treatments including intravenous gammaglobulin, steroids, and splenectomy may be used in management, although their indications and relative efficacy have been widely debated. ${ }^{8}{ }^{9}$ In each case the decision to treat depends on an analysis of the risks and benefits for the individual.

This analysis would be aided if objective criteria, which define the likelihood of a child with idiopathic thrombocytopenic purpura progressing to chronic disease, could be established at presentation or early in their clinical course. Reviewers of the subject have frequently noted the difficulty of determining this while mentioning clinical features suggestive of the acute form of childhood idiopathic thrombocytopenic purpura that they observed in their practice. Sex, age, duration of symptoms, season of onset, and associated viral illness are often cited. ${ }^{810} 11$ We identified a retrospective cohórt of 289 children with idiopathic thrombocytopenic purpura and studied, with statistical methods, these factors' predictive value for the development of chronic disease.

\section{Patients and methods}

All patients identified as having idiopathic thrombocytopenic purpura seen at the Royal Children's Hospital, Melbourne, Australia from 1968 to 1987 were reviewed; a total of 363 patients. Melbourne is a city of approximately 3 million people and we estimate that $90 \%$ of children from Melbourne and surrounding country areas with signs and symptoms suggestive of idiopathic thrombocytopenic purpura would have presented directly or have been referred to the Royal Children's Hospital. Fifty three patients who were not followed up at this hospital after discharge were excluded as were 13 patients who were referred after diagnosis for second opinion or for surgery. These 13 tertiary referred patients were excluded to enable accurate documentation of patient characteristics at initial presentation. A further eight patients were excluded from the logistic regression analysis because they could not be classified as acute or chronic using our study definition; seven of these patients underwent splenectomy after a brief, fulminant course during the acute illness and one died two months after diagnosis. These cases were included in descriptions of treatment and of complications in the cohort.

The diagnosis of idiopathic thrombocytopenic purpura was established by a history of increased bruising, petechiae and, in many cases, mucous membrane bleeding together with a platelet count $<50 \times 10^{9} / 1$. Children in 
whom there was another haematological disorder or systemic illness, other than intercurrent viral infection, to which the thrombocytopenia could be attributed were excluded. None of the study patients had positive family histories for collagen vascular disease, thrombocytopenia, or other haematological disorders. Bone marrow aspiration was performed in 237 $(82 \%)$ of patients, including all of those who were later classified as having chronic idiopathic thrombocytopenic purpura. In all cases the bone marrow showed normal erythropoiesis and granulopoiesis, normal or increased numbers of megakaryocytes, few free platelets, and no evidence of neoplasia or aplasia.

Case records were examined to ascertain the following information: age, sex, season of symptoms onset, the duration and nature of symptoms from first observation to presentation at the Royal Children's Hospital, signs at presentation, history of viral illness in the four weeks before onset of syptoms, complications, sequential platelet counts, treatment, and outcome. Outcome was classified as acute or chronic, the latter being defined as persistent or recurrent thrombocytopenia (platelet count $<150 \times 10^{9} / 1$ ) for more than six months after presentation. We had intended to include the platelet count at diagnosis in our analysis but had to discard this variable because $98 \%$ of our study cohort had initial platelet counts $<20 \times 10^{9} / 1$.

Initially a crude odds ratio was calculated for the contribution of each variable to outcome. Exact confidence intervals and, where applicable, trend tests were also determined. The odds ratio gives an estimate of disease (outcome) probability for a particular exposure (variable) and approximates the relative risk (in this study of the child going on to chronic idiopathic thrombocytopenic purpura). In order to produce an estimate of the effects of interest, which was more precise and less biased by confounding, unconditional logistic regression ${ }^{12}$ was carried out using the Egret software package. ${ }^{13}$

\section{Results}

Of the 289 children with idiopathic thrombocytopenic purpura in our study, $236(82 \%)$ were classified as having acute idiopathic thrombocytopenic purpura and $53(18 \%)$ as having chronic idiopathic thrombocytopenic purpura. Mean follow up time for patients with acute disease was 5.5 months after platelet counts had returned to normal (range 2-29 months). Chronic patients were followed up for extended periods, most for longer than four years.

The cohort characteristics are summarised in table 1. Most of the viral illnesses occurring within the four weeks before the child presenting with thrombocytopenia were upper respiratory tract infections but eight patients had infectious mononucleosis diagnosed by heterophil antibody screening test and 11 patients had clear clinical evidence of varicella. Other viral exanthems as antecedents were noted in a further 15 patients but descriptions and laboratory studies were inadequate for further characterisation.

\section{PREDICTORS OF CHRONIC DISEASE}

The variables age, sex, season of onset, association with viral illness, and length of symptoms were included in the logistic regression analysis. Table 1 shows the crude (unadjusted) odds ratio and adjusted odds ratio for each variable. As shown, results of trend tests for age and for length of symptoms at presentation were highly significant.

\section{OUTCOME}

Table 2 gives crude and adjusted odds ratios for the likelihood of having chronic idiopathic thrombocytopenic purpura if platelet counts were $<50 \times 10^{9} / 1$ or $<150 \times 10^{9} / 1$ at 28 days and three months after presentation. For the analyses at three months, duration of symptoms,

Table 1 Risk factors compared with outcome

\begin{tabular}{|c|c|c|c|c|c|c|c|c|c|}
\hline & \multirow[b]{2}{*}{$\begin{array}{l}\text { Total } \\
(n=289)\end{array}$} & \multicolumn{2}{|l|}{ Outcome } & \multirow[b]{2}{*}{$\begin{array}{l}\text { Crude } \\
\text { odds } \\
\text { ratioł }\end{array}$} & \multirow[b]{2}{*}{$\begin{array}{l}95 \% \\
\text { Confidence } \\
\text { intervals }\end{array}$} & \multirow{2}{*}{$p$ Value } & \multirow[b]{2}{*}{$\begin{array}{l}\text { Adjusted } \\
\text { odds ratioł } \neq\end{array}$} & \multirow[b]{2}{*}{$\begin{array}{l}95 \% \\
\text { Confidence } \\
\text { intervals }\end{array}$} & \multirow[b]{2}{*}{ p Value } \\
\hline & & $\begin{array}{l}\text { Chronic } \\
(n=53)\end{array}$ & $\begin{array}{l}\text { Acute } \\
(n=236)\end{array}$ & & & & & & \\
\hline \multicolumn{10}{|l|}{ Sex: } \\
\hline Male & 163 & 27 & 136 & & & & & & \\
\hline \multicolumn{3}{|l|}{ Age (years): } & & $0 \cdot 8$ & 0.04 to 1.4 & $0 \cdot 4$ & 0.9 & 0.5 to 1.8 & $0 \cdot 8$ \\
\hline $0.5-3$ & Mean age & 16 & 91 & & & & & & \\
\hline $\begin{array}{c}4-7 \\
8-11 \\
12-15\end{array}$ & $\begin{array}{l}=5 \text { years } \\
\text { (range } 0 \cdot 5-15)\end{array}$ & $\begin{array}{r}19 \\
12 \\
6\end{array}$ & $\begin{array}{r}100 \\
31 \\
14\end{array}$ & $\begin{array}{l}1 \cdot 1 \\
2 \cdot 2 \\
2 \cdot 4^{*}\end{array}$ & $\begin{array}{l}0.5 \text { to } 2.4 \\
0.9 \text { to } 5.6 \\
0.7 \text { to } 8.0\end{array}$ & $\begin{array}{l}0 \cdot 8 \\
0 \cdot 1 \\
0 \cdot 1\end{array}$ & $\begin{array}{l}1 \cdot 2 \\
1 \cdot 9 \\
2 \cdot 3\end{array}$ & $\begin{array}{l}0.5 \text { to } 2.7 \\
0.7 \text { to } 2.9 \\
0.6 \text { to } 8.8\end{array}$ & $\begin{array}{l}0 \cdot 7 \\
0 \cdot 2 \\
0 \cdot 2\end{array}$ \\
\hline \multicolumn{10}{|l|}{$\begin{array}{l}\text { Viral illness in four } \\
\text { four weeks before } \\
\text { presentation: }\end{array}$} \\
\hline Yes & 179 & 22 & 157 & & & & & & \\
\hline No & 110 & 31 & 79 & $2 \cdot 8$ & 1.5 to 5.4 & $<0.001$ & $1 \cdot 5$ & 0.7 to 2.9 & $0 \cdot 3$ \\
\hline \multicolumn{10}{|c|}{$\begin{array}{l}\text { Season of symptom } \\
\text { onset: }\end{array}$} \\
\hline Summer & 79 & 19 & 60 & & & & & & \\
\hline Autumn & 49 & 9 & 40 & $0 \cdot 7$ & 0.3 to 1.8 & 0.5 & 0.6 & 0.2 to 1.7 & 0.3 \\
\hline Winter & 84 & 12 & 72 & 0.5 & $0 \cdot 2$ to $1 \cdot 3$ & $0 \cdot 2$ & $0 \cdot 8$ & $0 \cdot 3$ to $2 \cdot 1$ & $0 \cdot 7$ \\
\hline \multirow{2}{*}{\multicolumn{10}{|c|}{$\begin{array}{l}\text { Duration of } \\
\text { symptoms (days): } \\
0-7\end{array}$}} \\
\hline & & & & & & & & & \\
\hline $\begin{array}{l}8-14 \\
>14\end{array}$ & $\begin{array}{r}41 \\
42\end{array}$ & $\begin{array}{r}9 \\
26\end{array}$ & $\begin{array}{l}32 \\
16\end{array}$ & $\begin{array}{c}2 \cdot 9 \\
16 \cdot 6^{* *}\end{array}$ & $\begin{array}{l}1 \cdot 1 \text { to } 7 \cdot 6 \\
7 \cdot 2 \text { to } 40 \cdot 3\end{array}$ & $\begin{array}{c}0.02 \\
<0.001\end{array}$ & $\begin{array}{r}2 \cdot 8 \\
14 \cdot 9\end{array}$ & $\begin{array}{l}1 \cdot 2 \text { to } 7 \cdot 2 \\
6 \cdot 3 \text { to } 35\end{array}$ & $\begin{array}{c}0.03 \\
<0.001\end{array}$ \\
\hline
\end{tabular}

${ }^{*}$ Trend test $\mathrm{p}=0.04 ;{ }^{* *}$ trend test $\mathrm{p}=0.001$.

thogistic regression model for each adjusted odds ratio contained all variables listed in table.

$\ddagger$ Reference value for all odds ratios is first variable category. 
Table 2 Platelet counts at 28 days and three months compared with outcome

\begin{tabular}{|c|c|c|c|c|c|c|}
\hline & \multicolumn{2}{|l|}{ Outcome } & \multirow{2}{*}{$\begin{array}{l}\text { Crude } \\
\text { odds } \\
\text { ratio* }\end{array}$} & \multirow{2}{*}{$\begin{array}{l}95 \% \\
\text { Confidence } \\
\text { intervals }\end{array}$} & \multirow{2}{*}{$\begin{array}{l}\text { Adjusted } \\
\text { odds ratio }{ }^{*} t\end{array}$} & \multirow{2}{*}{$\begin{array}{l}95 \% \\
\text { Confidence } \\
\text { intervals }\end{array}$} \\
\hline & $\begin{array}{l}\text { Chronic } \\
(n=53)\end{array}$ & $\begin{array}{l}\text { Acute } \\
(n=236)\end{array}$ & & & & \\
\hline $\begin{array}{l}\text { Platelet count at } 28 \text { days }\left(\times 10^{9} / 1\right) \text { : } \\
\quad<50 \\
\geqslant 50 \\
<150 \\
\geqslant 150\end{array}$ & $\begin{array}{l}32 \\
21 \\
41 \\
12\end{array}$ & $\begin{array}{r}47 \\
189 \\
112 \\
126\end{array}$ & $\begin{array}{l}6 \cdot 3 \\
3.9\end{array}$ & $\begin{array}{l}3.6 \text { to } 12 \cdot 7 \\
1.9 \text { to } 8.6\end{array}$ & $\begin{array}{l}5 \cdot 1 \\
3 \cdot 6\end{array}$ & $\begin{array}{l}2.4 \text { to } 10 \cdot 7 \\
1.6 \text { to } 8.0\end{array}$ \\
\hline $\begin{array}{l}\text { Platelet count at three months }\left(\times 10^{9} / 1\right) \text { : } \\
\quad<50 \\
\geqslant 50 \\
<150 \\
\geqslant 150\end{array}$ & $\begin{array}{r}36 \\
17 \\
46 \\
7\end{array}$ & $\begin{array}{r}8 \\
228 \\
25 \\
211\end{array}$ & $\begin{array}{l}57 \cdot 8 \\
54 \cdot 0\end{array}$ & $\begin{array}{l}22 \cdot 3 \text { to } 168 \cdot 1 \\
21 \cdot 3 \text { to } 157 \cdot 5\end{array}$ & $\begin{array}{r}158 \cdot 4 \\
78 \cdot 6\end{array}$ & $\begin{array}{l}40.9 \text { to } 61.3 \\
23.9 \text { to } 257.3\end{array}$ \\
\hline
\end{tabular}

${ }^{*}$ Reference value for all odds ratios is first variable category: p values for all crude and adjusted odds ratios were $<0.001$.

†Logistic regression model for each adjusted odds ratio contained all variables listed on table 1.

associated viral illness, and age contributed most to the positive confounding in the crude odds ratio for platelet counts $<50 \times 10^{9} / 1$ and duration of symptoms together with age increased the crude odds ratio for platelet counts $<150 \times 10^{9} / 1$

At 28 days after diagnosis $136(47 \%)$ of the study cohort had normal platelet counts. By three months $218(75 \%)$ had normal platelet counts (228 of the acute group and seven of the chronic group). Five of these seven children who were later classified as chronic but had a normal platelet count at three months were on steroids at that time and two had received a gammaglobulin infusion just before the blood count. Of the five children on steroids, four had been restarted on this drug because of persistent severe thrombocytopenia after initial steroid treatment and one had begun steroids after a period of prolonged observation without resolution of thrombocytopenia.

Two thirds of the children with chronic idiopathic thrombocytopenic purpura still had thrombocytopenia two years after diagnosis (four cases had incomplete follow up for two years). Ten of the 14 children who had recovered had undergone splenectomy.

\section{TREATMENT}

Treatment of idiopathic thrombocytopenic purpura changed considerably between 1967 and 1987. Up until 1973 steroids (prednisolone $2 \mathrm{mg} / \mathrm{kg} /$ day for four weeks and then tapered) were given to 80 to $90 \%$ of new patients at presentation. In subsequent years 10 to $50 \%$ of new cases each year received steroids at some time in their management. It was not possible to study the effect of steroids in treating idiopathic thrombocytopenic purpura without introducing bias through confounding. This was because treatment allocation in this study was not based on a random process but by deliberate assignment to individuals who were thought to be most likely to benefit from it, thus causing potential confounding by indication. ${ }^{14}$

Seventeen patients were treated with intravenous gammaglobulin: three in 1985, five in 1986 , and nine in 1987. Four of these had one five day course for clinically severe bleeding at presentation and 13 patients with chronic idiopathic thrombocytopenic purpura had multiple two or five day courses. Five of this latter group subsequently underwent splenec- tomy. Again the possibility of confounding by indication prevented analysis of efficacy.

Splenectomy was performed in 33 cases; in seven it was performed less than six months after diagnosis because of fulminant disease which failed to respond to high dose steroids, and in 26 cases the surgery was delayed for greater than six months after diagnosis. The idiopathic thrombocytopenic purpura resolved in all seven patients who had surgery less than six months after diagnosis and in 16 of those operated on after six months. There were no perioperative complications or long term complications, such as septicaemia, after a mean follow up of $4 \cdot 4$ years (range $0 \cdot 5-8$ years). After the introduction of intravenous gammaglobulin in 1985 no further early splenectomies were performed. The timing of splenectomy in the 26 patients with chronic idiopathic thrombocytopenic purpura varied widely, the average being 16 months after diagnosis (range 9-36 months). The mean age at which surgery was performed was nine years (range 7-14 years). Indications for splenectomy in this group were predominantly for persistent platelet counts of $<50 \times 10^{9} / 1$ with ongoing skin bleeding and need for restriction of physical activities.

\section{COMPLICATIONS}

Skin bleeding alone was the only abnormal sign at presentation in $173(60 \%)$ cases, the other 116 also had mucosal bleeding. Eight patients had haematemesis and melaena. Blood transfusions were given in less than $5 \%$ of patients. Only three of the children with chronic idiopathic thrombocytopenic purpura required readmission to the Royal Children's Hospital for problems related to thrombocytopenia, other than for gammaglobulin infusion or splenectomy. Two of these patients who were readmitted with chronic idiopathic thrombocytopenic purpura died of cerebral haemorrhage, as discussed below; the other child was admitted for bedrest because of continued severe bruising and epistaxis.

Three children (1\%) died of intracranial haemorrhage, all in the period before the availability of gammaglobulin. Each of these patients had had a bone marrow examination that was consistent with idiopathic thrombocytopenic purpura. The first was a 9 month old boy who presented with a five day history of bruising, petechiae and gum bleeding in association with 
a respiratory tract infection. He was started on steroids but platelet counts were still $<5 \times 10^{9} / 1$ four weeks after diagnosis. One week later he fell and hit his head sustaining a large subdural haematoma. Surgical evacuation was followed by uncontrollable fatal haemorrhage. The second death occurred in a girl of 3.8 years who was first seen with a long history of recurrent epistaxis and of two weeks of skin bruising. Despite steroid administration platelet counts remained $<5 \times 10^{9} / 1$ over the next eight months. Requests for permission for splenectomy were refused. Eleven months after diagnosis she was admitted with massive oral and skin bruising and haematemesis and died before splenectomy could be undertaken. Necropsy confirmed intracranial haemorrhage. The other death was a 4 year old girl who presented with four months of excessive bruising. Steroids were given and the platelet count had returned to normal by day 14 and remained so after weaning from steroids at one month. Two further courses of steroids were administered at nine and 16 months when the platelet count again fell to $<10 \times 10^{9} / 1$ and bruising recurred. A splenectomy was performed at 18 months and there was a transient rise in platelet counts to normal but three months later the count was $15 \times 10^{9} / 1$. The count returned to normal when steroids were again given. After a further two months steroids were weaned and six weeks later the child had a brief gastroenteritis like illness and suffered a fatal cerebral haemorrhage.

\section{Discussion}

In this historical cohort study of childhood idiopathic thrombocytopenic purpura, 53 $(18 \%)$ of the children reviewed had continuing thrombocytopenia six months after presentation. The mortality rate was $1 \%$, with one death from intracranial haemorrhage occurring at eight weeks after diagnosis and two deaths from intracranial haemorrhage occurring during the chronic phase of the illness. These figures are similar to those found in previous studies. ${ }^{1-3} 15$ The benign nature of acute and chronic childhood idiopathic thrombocytopenic purpura, aside from the small ongoing risk of intracranial haemorrhage, is generally recognised. ${ }^{48}$ Major medical complications in our cohort were few, as indicated by the small number of readmissions, other than for treatment, for problems related to thrombocytopenia. The exclusion of tertiary referred patients and the role of the Royal Children's Hospital as the only major paediatric hospital in the study community minimised selection bias towards the chronic idiopathic thrombocytopenic purpura group.

Remission after splenectomy occurred in 23 out of $33(70 \%)$ cases, a figure similar to that reported elsewhere. ${ }^{5} 10$ The $100 \%$ remission rate in children splenectomised early in the course of their illness reflects the differences in the indications for this procedure between the acute and chronic groups. In the former group splenectomy was usually undertaken because of severity rather than chronicity of disease and, had it been possible to avoid the surgery, spontaneous remission may well have occurred.
Early splenectomy as a treatment for severe, life threatening haemorrhage may become even less common now that gammaglobulin is available.

In our search for patient characteristics at presentation that were predictive of chronic idiopathic thrombocytopenic purpura we noted that patients tended to separate into two groups-those who took many days to present in whom onset of bruising was gradual and progressive and mucosal bleeding was less common, and those who presented early, often on the day of symptom onset and who had dramatic, widespread ecchymoses and bleeding. We calculated an adjusted odds ratio of 14.9 for a history of symptoms for greater than 14 days at presentation to the Royal Children's Hospital indicating a strong association between this variable and eventual chronic outcome. The positive trend test showed that if symptoms had been present for between one and two weeks there was also an increased risk of chronicity. Whether these two groups with differing modes of onset of thrombocytopenic symptoms represent disease subtypes with different pathogenesis is not known. Walker and Walker also used the criterion of a history of bleeding for $>14$ days at presentation to subdivide their patients in a long term follow up study of childhood idiopathic thrombocytopenic purpura. ${ }^{6}$ As in our study, they found the two groups of patients differed considerably in their outcome, with $91 \%$ of the group with symptoms for $>14$ days of symptoms remitting spontaneously compared with $36 \%$ of the group with longer symptom histories.

Associated viral illness, sex of the patient, and season of onset were not predictive of outcome when adjusted odds ratios were calculated. The numbers in the oldest age group were small and the study showed a trend towards greater risk of chronicity with increasing age, although odds ratios were not significant.

A total of $218(75 \%)$ of the total cohort had normal platelet counts three months after diagnosis, with nearly all the children who were classified as having acute idiopathic thrombocytopenic purpura having recovered. Of the children classified as having chronic idiopathic thrombocytopenic purpura on the basis of six months of thrombocytopenia, two thirds, irrespective of treatment, still had thrombocytopenia two years after diagnosis. Recovery was spontaneous in a few and occurred after splenectomy in others. Is there a time short of six months when the course of idiopathic thrombocytopenic purpura in children might be predicted? Our analysis documented that at 28 days the risk of chronic disease was trebled in the group with platelet counts between 50 and $150 \times 10^{9} / 1$ and five times as likely if counts were $<50 \times 10^{9} / 1$. When early treatment with gammaglobulin is instituted other factors such as initial response to treatment and time to relapse of the platelet count may provide additional useful information regarding long term outcome; to our knowledge such information is not yet available.

The conclusions that may be drawn from this study are that, of the five patient characteristics that we studied which were thought to be 
related to outcome in childhood idiopathic thrombocytopenic purpura, only symptoms for $>14$ days at presentation was useful in prediction of chronicity when confounding between variables was accounted for in the analysis. We did not demonstrate clear predictive value for age greater than 10 years at diagnosis but analysis was limited by small sample sizes for the older age groups.

The study also established that ongoing subnormal platelet counts 28 days after diagnosis increased the risk of prolonged thrombocytopenia. This risk was greater in the group with very low platelet counts. Most of our cohort had normal platelet counts by three months after diagnosis. If they did not, continuing thrombocytopenia was likely. This information may be useful to paediatricians managing children with idiopathic thrombocytopenic purpura for counselling patients and their parents and in planning treatment.

We would like to thank Dr T Nolan for his help with the statis tical analysis and review of the manuscript and Drs $H$ Ekert and GP Tauro for their helpful comments and criticisms.

1 Lusher JM, Zuelzer WW. Idiopathic thrombocytopenic purpura in childhood. $\mathcal{F}$ Pediatr 1966;68:971-9.
2 Walker JH, Walker W. Idiopathic thrombocytopenic purpura in childhood. Arch Dis Child 1961;36:649-57.

3 Lammi AT, Lovric VA. Idiopathic thrombocytopenic purpura: an epidemiologic study. 7 Pediatr 1973;83:31-6.

4 Lilleyman JS. Management of childhood idiopathic thrombocytopenic purpura. Br F Haematol 1983;54:11-4.

5 Russell EC, Maurer HM. Alternatives to splenectomy in the management of chronic idiopathic thrombocytopenic management of chronic idiopathic thrombocytopenic
purpura in childhood. Am $\mathcal{f}$ Pediatr Hematol Oncol 1984;6: purpura

6 Walker RW, Walker W. Idiopathic thrombocytopenia, initial illness and long term follow up. Arch Dis Child 1984;54: illness and

7 Woerner SJ, Abildgaard HD, French BN. Intracranial haemorrhage in children with idiopathic thrombocytopenic purpura. Pediatrics 1981;67:453-60.

8 Buchanan GR. The non treatment of childhood idiopathic thrombocytopenic purpura. Eur $\mathcal{f}$ Pediatr 1987;146: 107-12.

9 Ware R, Kinney TR. Therapeutic considerations in childhood idiopathic thrombocytopenic purpura. CRC Crit Rev Oncol Hematol 1987;7:139-52.

10 Lusher JM, Iyer RK. Idiopathic thrombocytopenic purpura in children. Semin Thromb Hemost 1977;3:175-99.

11 Lusher JM, Warrier I. Use of intravenous gamma globulin in children and adolescents with idiopathic thrombocytopenic purpura and other immune thrombocytopenias. $\mathrm{Br} f$ purpura and other immune thro

12 Breslow NE, Day NE. Statistical methods in cancer research, volume 1 - the analysis of case control studies. Lyon: IARC, volume 1-the

13 Anonymous. Egret users manual. Seattle: Statistics and Epidemiology Research Corporation, 1988.

14 Miettinen OS. The need for randomization in the study of intended effects. Stat Med 1983;2:267-71.

15 Benham ES, Taft LI. Idiopathic thrombocytopenic purpura in children: results of steroid therapy and splenectomy. Aust Paediatr $\mathcal{F}$ 1972;8:311-7. 